\title{
MUSIK OGLOR DALAM RITUAL SUNATAN DI DESA WONOKARTO KECAMATAN NGADIROJO KABUPATEN PACITAN
}

\author{
Zhenley Octa Sinaga ${ }^{1}$
}

\begin{abstract}
Oglor is one of the traditional arts that developed in the village community Wonokarto, in this case Oglor music is used as a means of circumcision ritual in the village Wonokarto. Where the owner of the intent more believes with chanting poem played Oglor music will be faster delivered to God. The form of music presentation Oglor in the ceremony sunatan as a means of accompaniment, bringing many songs and Islamic poems taken from the book barzanji. Oglor music has always been used as a medium of prayer in the great days of religion and especially for traditional ceremonies in the village of Wonokarto. The call of poetry containing prayers with the accompaniment of kendang, centrifugal and flying instruments into an inseparable unity. Thus it can be concluded that Oglor as a means of ritual circumcision ceremony in Wonokarto village is one of the tradition of Wonokarto villagers, where the owner chooses to bring Oglor music in every ritual ceremony of sunatan ceremony. Because every verse of the song that is sung has meaning for the good of the child in the future and is celebrated as gratitude to God Almighty.
\end{abstract}

Keyword: Music Oglor, Ritual sunatan, Wonokarto Society

\begin{abstract}
Abstrak
Oglor adalah salah satu kesenian tradisional yang berkembang di masyarakat desa Wonokarto, dalam hal ini musik Oglor digunakan sebagai sarana ritual sunatan di desa Wonokarto. Dimana pemilik hajat lebih percaya dengan lantunan syair yang dimainkan musik Oglor akan lebih cepat tersampaikan kepada Allah. Bentuk penyajian musik Oglor di dalam upacara sunatan sebagai sarana pengiring, banyak membawakan lagu dan syair-syair Islam yang diambil dari kitab barzanji. Musik Oglor selalu digunakan sebagai media penghantar doa dihari besar agama dan terutama untuk upacara adat di desa Wonokarto. Seruan syair yang berisi doa dengan iringan instrumen kendang, sentik dan terbang menjadi satu kesatuan yang tak terpisahkan. Dengan demikian dapat disimpulkan bahwa Oglor sebagai sarana
\end{abstract}

${ }^{1}$ Mahasiswa Jurusan Etnomusikologi, Fakultas Seni Pertunjukan, Institut Seni Indonesia Yogyakarta, e-mail: zhenleysinaga@gmail.com 
upacara ritual sunatan di desa Wonokarto merupakan salah satu tradisi masyarakat desa Wonokarto, dimana pemilik hajat memilih menghadirkan musik Oglor pada setiap prosesi upacara ritual sunatan. Karena setiap syair lagu yang dilantunkan memiliki arti untuk kebaikan anak kedepannya dan dirayakan sebagai rasa syukur kepada Tuhan Yang Maha Esa.

Kata Kunci: Musik Oglor, Ritual sunatan, Masyarakat Wonokarto

\section{Pendahuluan}

Seni musik Oglor yang berkembang di kabupaten Pacitan, khususnya di kecamatan Ngadirojo desa Wonokarto ini merupakan kesenian yang bernafaskan Islam dalam kebudayaan Jawa, yang memiliki makna mendalam di dalam setiap penyajiannya. Kesenian musik Oglor ini mirip dengan kesenian Sholawat, hanya saja tidak menggunakan rebana kecil. Sholawat menurut kamus umum bahasa Indonesia juga berasal dari bahasa Arab (jamak dari sholat), yang berarti doa (seruan) untuk memohon berkat dari Tuhan (Purwadarminta, 1984:894). Kesenian ini mempunyai nilai spesifik bagi masyarakat Jawa, karena tembang syairnya terkait untuk menghadapi masalah-masalah kehidupan (Dadori Amin, 2002:73).

Musik Oglor pada awalnya hanya digunakan sebagai media dakwah agama Islam, namun perkembanganya mulai digunakan juga untuk sarana upacara ritual di masyatakat desa Wonokarto atau yang sering disebut dengan slametan (selamat) oleh masyarakat Jawa, terutama di desa Wonokarto. Dari perkembangan yang dilalui tradisi Oglor itu sendiri, untuk kebutuhan hiburan yang dipertontonkan terdapat penambahan seni tari pada penyajiannya.

Penyajian musik Oglor dalam ritual sunatan(khitanan) di desa Wonokarto menggunakan alat musik 3 (tiga) Terbang, 1 (satu) Kendang, 1 (satu) Sentik. Kata Oglor berasal dari bunyi instrumen terbang yang dimainkan dan menghasikan suara “Glor-Glor" (Wawancara dengan Wito, 6 September 2017). Peranan instrumen kendang sebagai pemimpin intrumen lainnya, karena instrumen kendang dalam musik 
Oglor memiliki banyak warna suara yang dihasilkan dari pada instrumen terbang dan sentik. ritme dan pola pukulan instrumen terbang satu dengan yang lainya sama dan peranan instrumen sentik, mengimbal dari pola pukulan instrumen kendang.

Para pemain di dalam musik Oglor ini hanya dimainkan oleh laki-laki dan rata-rata berumur 50 hingga 70 tahun. Karena kematangan dan pengalaman pemain dalam memainkan alat musik serta melantunkan doa dengan fasih dipercaya masyarakat desa Wonokarto dapat melancarkan jalannya prosesi ritual sunatan. Di dalam ritual sunatan ini peranan pemain sangat penting untuk proses berjalannya ritual dari awal hingga akhir.

Lantunan syair yang dinyayikan para pemain di dalam musik Oglor memiliki keunikan tersendiri, yaitu dengan usia yang tua tetapi bisa mencapai nada vokal yang tinggi. Rahasia para pemain untuk bisa mencapai nada vokal yang tinggi, yaitu sebelum melakukan ritual mereka melakukan gurah sambel yang dipersiapkan dari satu hari sebelum ritual dilaksanakan dan diminum sebelum melaksanakan prosesi ritual sunatan.

Musik Oglor tidak bisa lepas dari proses perpaduan dua budaya, yakni budaya Jawa dan budaya Timur Tengah. Musik Oglor itu sendiri adalah kesenian yang menggunakan vokal syair Timur Tengah (Arab) dilantunkan dengan nada pentatonis (Jawa). Kesenian Oglor memiliki banyak lagu atau tembang dan di dalam setiap lagu memiliki makna yang mendalam sebagai pengajaran kepada umat Islam agar senantiasa taat kepada Tuhan. Lagu yang merupakan ciri khas musik Oglor yaitu lagu Ngindama (Wawancara dengan Tumiran, 9 November 2017). Lagu Ngindama adalah lagu yang paling sering dimainkan musik Oglor untuk penyebaran agama Islam di desa Wonokarto dan memperingati acara Maulid Nabi, terutama untuk acara ritual di masyarakat desa Wonokarto. 


\section{Masyarakat Desa Wonokarto dan Musik Oglor Dalam Ritual Sunatan}

Kesenian Oglor adalah kesenian tradisi yang awal keberadanya diciptakan oleh Dul Patah (almarhum), seorang Kyai dari desa Wonodadi kecamatan Ngadirojo. Dul Patah pada awalnya adalah seorang pendatang dari kabupaten Ponorogo, yang kemudian menetap di desa Wonodadi kecamatan Ngadirojo kabupaten Pacitan. Dalam rangka penyebaran agama Islam di wilayah tersebut, namun upaya Kyai Dul Patah dalam berdakwah, banyak menemukan kendala, seperti masyarakat yang masih sulit untuk menerima ataupun mempelajari ajaran agama Islam hingga ahirnya Kyai Dul Patah menemukan sebuah ide untuk berdakwah yaitu dengan mengunakan media kesenian musik untuk memikat hati masyarakat agar tertarik dengan ajaran agama Islam yang di sampaikan. Kesenian musik tersebut menggunakan alat musik 2 (dua) terbang gede dan 1 (satu) kendang Jawa dan kemudian di beri nama Seni Oglor (Wawancara dengan Wito, 6 September 2017). Sehingga seni Oglor merupakan satu kesenian yang sengaja diciptakan Kyai Dul Patah sebagai sarana dakwah. Penyebaran agama Islam di desa Wonodadi kecamatan Ngadirojo kabupaten Pacitan.

Seni Oglor sebagai sarana dakwah ternyata menarik perhatian masyarakat desa Wonodadi. Banyak masyarakat desa Wonodadi yang kemudian dapat mengenal dan mulai mempelajari agama Islam. Dalam perkembangannnya kemudian, masyarakat desa Wonodadi merupakan masyarakat yang mayoritas memeluk agama Islam. Karena kesenian Oglor mendapat tempat dihati masyarakat desa Wonodadi, akhirnya Kyai Dul Jais dari desa Wonokarto mendatangi Kyai Dul Patah untuk mempelajari kesenian Oglor yang kemudian akan di terapkan di desa Wonokarto setelah Kyai Dul Jais mempelajari dan menerapkanya di desa Wonokarto ternyata respon masyarakat Wonokarto sangat bagus hingga di desa Wonokarto mempunyai group kesenian Oglor. Dalam penanganan Kyai Dul Jais, kesenian Oglor tidak saja digunakan sebagai dakwah agama Islam, namun mulai digunakan juga untuk sarana ritual-ritual desa, seperti ritual nyapih (upaya menghentikan seorang ibu dalam proses menyusui bayi), ritual mitoni / tingkeban (peringatan tujuh bulan ibu hamil), manten, 
ritual sunatan (khitanan) dan lainnya. Berbagai acara ritual masyarakat desa Wonokarto tidak lepas dengan kehadiran seni Oglor sebagai media utamanya. Sehingga seni Oglor dapat hidup berdampingan dengan acara-acara tradisi masyarakat desa Wonokarto.

Usia Kyai Dul Jais mendekati lanjut, kemudian perjuangan Kyai Dul Jais dalam mempresentasikan seni Oglor untuk berdakwah dilanjutkan oleh salah satu muridnya, yaitu Kartono (80 tahun). Di masa penanganan Kartono, seni Oglor mengalami penurunan peminat yang ditandai dengan berkurangnya jumlah group seni Oglor yang ada di desa Wonokarto. Walaupun demikian Kartono tidak tinggal diam Kartono mencoba untuk membangkitkan lagi gairah masyarakat agar kembali mencintai kesenian Oglor. Kartono melakukan tindakan nyata yaitu dengan penambahan jumlah instrumen yang digunakan, yaitu menambah instrumen terbang gede menjadi tiga buah, satu buah instrumen Kendang besar, satu buah Sentik. Melalui penambahan instrumen yang dilakukan, maka seni Oglor menjadi lebih banyak mempunyai variasi suara yang dihasilkan oleh setiap instrumen yang digunakan. Sehingga masyarakat menjadi lebih tertarik lagi terhadap kesenian Oglor.

Usia Kartono memasuki usia lanjut, kemudian seni Oglor dilanjutkan oleh salah satu keturunanya yaitu Tumiran (60 tahun). Dimasa Tumiran, kesenian Oglor masih populer di masyarakat Desa Wonokarto. Namun oleh karena perkembangan jaman, kesenian Oglor mulai ditinggalkan masyarakat, bahkan muncul anggapan seni Oglor adalah seni yang sudah kuno. Sehingga Tumiran berkolaborasi dengan M. Kasim untuk menambah tarian dalam seni Oglor. M. Kasim adalah seniman tari yang berasal dari kecamatan Ngadirojo. M. Kasim kemudian mempunyai ide untuk mengemas kesenian Oglor menjadi sebuah kesenian yang terdiri dari seni musik dan seni tari, yang indah untuk dipertontonkan. Langkah kreatifitas tersebut kemudian menjadikan seni Oglor berkembang di kabupaten Pacitan, dan kemudian mulai di undang ke luar daerah, seperti ke Jakarta, Surabaya, Blitar, dan kota-kota lainnya. Seni Oglor berkembang dari sarana dakwah kemudian menjadi seni pertunjukan tradisi masyarakat kabupaten Pacitan hingga sekarang. 


\section{Bentuk Penyajian dan Fungsi Musik Oglor Dalam Ritual Sunatan}

Penyelenggaraan sunatan tidak terlepas dari aspek waktu pelakasanaan music Oglor itu digunakan. Waktu dianggap penting dan sakral dalam pelaksanaan musik Oglor dalam upacara ritual. Ritual dilakukan pada tanggal 12 November 2017 hari Minggu. Waktu ini adalah waktu dimana anak lahir dalam penanggalan Jawa atau yang sering disebut weton. Dengan tujuan anak menjadi lebih kuat dan selamat dalam menjalani kehidupan kedepannya. Musik Oglor pada ritual Sunatan di desa Wonokarto dilaksanakan pada pagi hari sekitar pukul 08.00 WIB sampai siang. Dilanjutkan Slametan setelah sholat Isya', yaitu pada pukul 20.00 WIB sampai selesai.

Kesenian Oglor tidak diaksanakan di atas panggung pementasan. Pelaksanaanya berada di rumah Bapak Fitri Nurcahyoko dan mengarak anak ke lepen(mata air). Prosesi pertama berada di teras depan rumah sebagai tempat awal pelaksanaan dan doa. Prosesi kedua mengarak anak menuju lepen untuk mandi yang dipercaya masyarakat desa Wonokarto bisa membersihkan diri dari hal-hal bersifat negatif. Prosesi terakhir berada di ruang tamu untuk slametan anak dan berdoa bersama supaya segala harapan dari keluarga anak dikabulkan oleh Tuhan Yang Maha Esa.

Kostum yang dipakai musik Oglor cukup sederhana, dalam penyajiannya musik Oglor mengenakan batik lengan panjang bermotif hijau serta kuning dengan bawahan celana panjang hitam dan memakai songkok. Dari kostum yang digunakan musik Oglor ini terlihat perpaduan dua budaya, seperti songkok yang digunakan yaitu mengadospi dari budaya Timur Tengah (Arab) atau yang sering digunakan menutupi kepala oleh masyarakat Islam ketika menunaikan sholat dan kemeja yang digunakan bermotif batik yang diadopsi dari budaya Jawa. terkadang juga memakai baju muslim bewarna putih, dari kostum yang seragam dan kompak ini lebih menarik untuk dipertontonkan. 
Para pemain kesenian Oglor memiliki anggota berusia 50 hingga 70 tahun ke atas dengan mayoritas bermata pencaharian sebagai petani. Dengan usia yang sudah matang dan lebih berpengalaman, dipercaya masyarakat desa Wonokarto sebagai media penghantar doa kepada Tuhan. Kematangan usia dan pengalaman sangat berpengaruh dalam musik Oglor ini dan tidak untuk anak muda, karena warna suara masih berubah untuk mencapai nada tinggi, sedangkan ciri khas musik Oglor yaitu vokal ngelik(Wawancara dengan Tumiran, 12 November 2017). Bisa dikatakan tingkat emosional usia remaja banyak yang labil, padahal menabuh terbang dalam musik Oglor memerlukan ati sing meneb (hati yang menjiwai) (Wawancara dengan Jaman, 12 November 2017). Dalam pelaksanaan pertunjukan tidak ada ketetapan mengenai siapa yang berperan sebagai pemusik, sehingga sering terjadi perpindahan formasi pemain. Hanya posisi vokal inti/pembuka tidak bisa digantikan karena selain kendang sebagai pemimpin tempo setiap isntrumen vocal inti/pembukan juga berperan sebagai pemimpin vokal lain dalam pertunjukan.Pemain merupakan salah satu unsur dalam suatu seni pertunjukan. Pemain memegang peranan penting terhadap jalannya pertunjukan. Pada penyajian musik kesenian Oglor dimainkan oleh 10 pemain, yang terdiri dari:

1) 1 vokal pangelik/vokal inti.

2) 7 vokal.(3 orang merangkap alat terbangan)

3) 1 kendang.

Tata letak penyajian musik Oglor memiliki dua bentuk yang dibedakan oleh tujuan disajikannya musik tersebut. Untuk tata letak pada saat mengarak anak pada ritual sunatan tidak ada posisi yang diatur dengan kata lain bebas, penempatan setiap instrument bisa dimana saja. Tata letak jika di panggung yang berbentuk persegi panjang terdiri dari dua baris yakni di baris di depan vokal sementara baris di belakang pemusik, sedangkan tata letak yang kedua berbentuk melingkar.

Tata letak berbentuk persegi panjang pada umumnya digunakan dalam kegiatan, seperti manten, serta hari besar keagaman yang diadakan di atas panggung. Tata letak yang berbentuk melingkar umumnya digunakan dalam hajatan warga 
masyarakat, seperti mitoni, slametan rumah, serta sunatan. Tata letak berbentuk melingkar biasanya dipertunjukan di dalam rumah maupun halaman rumah. Berikut adalah tata letak yang digunakan musik Oglor.

Instrumen musik merupakan suatu alat musik yang menghasilkan bunyi atau suara. Jenis instrumen yang akan dikaji dalam musik musik Oglor adalah instrumen membranophone. Penjelasan tentang instrumen membranophone, merupakan alat musik yang sumber bunyinya berupa selaput yang dibentang. Adapun instrumen yang digunakan dalam penyajian musik musik Oglor yaitu: kendang, sentik, terbang(rebana besar).

Menurut Rahayu Supanggah, tangga nada dalam dunia karawitan dikenal dengan istilah laras, sementara laras sendiri mempunyai makna jamak, yaitu laras bermakna sesuatu yang enak dan nikmat untuk didengarkan atau dihayati, laras bermakna tangga nada. Terdapat dua jenis laras utama dalam karawitan yaitu laras slendro dan pelog (Rahayu Supanggah, 2007:86).

Seni pertunjukan yang mengandung musikologis memiliki beberapa unsur yang dapat dipisah-pisahkan sehingga dapat diteliti. Musik Oglor merupakan salah satu seni pertunjukan Sholawat yang mengandung unsur-unsur musikal, sehingga maksud dari pemeriksaan di sini adalah pemeriksaan terhadap unsur-unsur musikologisnya, seperti; bentuk musik, struktur musik, pola permainan dan irama. Dalam musik Oglor yang menonjolkan vokal, maka tidak lepas dari unsur bahasa dan lirik serta unsur musikologisnya. Berikut adalah analisis musik dari musik Oglor.

Bentuk musik maksudnya adalah bentuk teks penyajian atau pertunjukan musik Oglor dalam ritual sunatan. Bentuk musik dapat berwujud instrumental atau biasa disebut dengan gending, vokal atau sekaran maupun campuran vokal-instrumental atau sekar gending. Uraian bentuk musik instrumental dapat mengacu pada konsep bentuk karawitan atau musik barat. Konsep bentuk karawitan meliputi bentuk lagu, struktur lagu, pola melodi, atau ritme dasar (balungan), ritme isian dan ritme hiasan.

Pola permainan merupakan sistem atau cara kerja dalam sebuah permainan suatu instrumen. Menurut Rahayu Supanggah, pola adalah istilah generik untuk 
menyebut satuan tabuhan ricikan dengan ukuran panjang tertentu dan yang telah memiliki kesan atau karakter tertentu(Rahayu Supanggah, 2009:248). Kesenian rakyat pada umumnya bersifat monoton yang cenderung berulang-ulang. Setiap instrumen memiliki pola yang monoton, namun dengan tempo yang disesuaikan dengan irama lagu. Hal ini terlihat dalam lagu Ngindama. Berikut pola permainan untuk terbang, kendang, dan sentik dalam lagu Ngindama:

Pola Permainan Bagian I:

Buka Kendang: tp t b

Kendang $\quad: \| t p$ t $b$ kt $p$ b $\|$

Rebana I, II, III : : . b . . b \|

Pola Permainan Bagian II:

Kendang :\| btpp dtpp btpp dtpp \|

Rebana I, II, III $\quad: \| \cdot \quad$ b $\quad \cdot \quad$ b $\|$

Pola Permainan Bagian III (Bagian Inti)

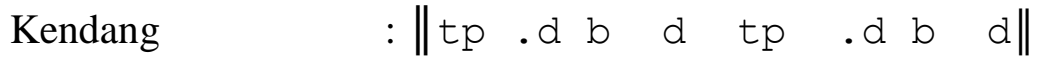

Rebana I, II, III $\quad: \| \cdot \quad$ • $\quad$.

Sentik $\quad:\|\cdot p \cdot p \cdot p \cdot p \cdot p \cdot p \cdot p \cdot p \cdot p \cdot p\|$

Pola Permainan Arak-arakan:

Kendang $\quad: \| \cdot p$ tp bp tp bp tp bp b\|

Rebana I, II, III $\quad: \| \cdot \quad \cdot \quad$ •

Sentik $\quad:\|\cdot p \cdot p \cdot p \cdot p \cdot p \cdot p \cdot p \cdot p \cdot p\|$ 
Keterangan:

t: tak: $\mathrm{p}$ : thung: $\mathrm{d}$ : den; b: dhang

Musik Oglor tidak menggunakan instrumen melodis dalam penyajiannya, tetapi sangat didominasi syair-syair yang dinyanyikan. syair-syair tersebut tentunya memiliki tangga nada. Tangga nada yang digunakan adalah tangga nada pentatonis.

Pada dasarnya masyarakat desa Wonokarto tidak mengenal ilmu musik. Keseluruhan metode pembelajaran melalui metode oral (mulut) yang langsung diajarkan seperti syair-syair dan pola tabuhan. Untuk pembelajaran syair masyarakat hanya mengandalkan pendengaran sehingga tidak ada kepastian nada yang bisa di ukur secara tepat, akan tetapi penulisan ini menggunakan penulisan yang ditulis berdasarkan hasil rekaman pada saat dilapangan.

Menganalisis musik diperlukan berbagai simbol-simbol untuk menggambarkan bunyi yang didengar. Simbol-simbol yang berwujud angka, huruf, maupun gambar inilah yang disebut dengan notasi. Untuk menganalisa musik Oglor ini menggunakan notasi kepatihan. Kepatihan sendiri merupakan penyebutan untuk sistem notasi karawitan Jawa yang dinyatakan dengan angka-angka.

Berikut adalah transkrip lirik lagu Ngindama.

Sae'olelah yala tobat sae,olelah...........

Pamurune Muhammadeyah...

dendang wong loro podho karepe (diulang $3 x$ )

Assalamuallaikum....

Yaa Nabi salam alaik...

Oooglor......

Ono Manuk.....kae noman.....elolaho...yoo no manuk...kae noman...elolaho...yoo manuke... manuk dandang elolaho...pencokanmu kayune roh sisir ginawe susuh

Elooo....... (ngelik)

Elooo...............

Ismanuruk...ismanuruk...amencoko lawang suwargo...anginoma segoro imo mbeber layar ono medhinah

Ngindama sadu makamil (makamil) wantana dali rokili (rokili) jitaham watan nusa ila (saila) kultukip liya dalilu (diulang $2 x$ ) 
Elooo.........(ngelik)

Elooo.............

Ismanuruk...ismanuruk...amencoko lawang suwargo...anginoma segoro imo mbeber layar ono medhinah

Nawaetu saoma godhir...

An'ada'I fardhi sahri...

Romadhona hadihissanati

fardlu lilahiwata'ala (diulang $2 x$ )

Eloooo........(ngelik)

Eloooo .................

Yalaelo haelolah...(2x) Mohammadhur rosulullah madun murka masya Allah...ngalaihi shalatulah Ya Allah Ya Rasulullah...

Elooo........(ngelik)

Eloooo.................

Yalaelo haelolah...(2x) Mohammadhur rosulullah madun murka masya Allah...ngalaihi shalatulah Ya Allah Ya Rasulullah...

Assalamuallaikum....

Yaa Nabi salam alaik...

Musik berfungsi sebagai suatu media bagi seseorang untuk mengungkapkan perasaan atau emosinya. Dengan kata lain, pemain dapat mengugkapkan perasaan atau emosi melalui musik. Pengungkapan rasa tersebut sebagai cara untuk membentuk sebuah suasana dalam setiap penyajiannya dan meberikan pengaruh untuk pendengarnya. Seperti halnya dalam ritual sunatan. Musik yang dimainkan secara berulang-ulang memberikan kesan terhadap anak menjadi tenang sebelum disunat. Nada vokal ngelik yang tinggi menjadikan anak lebih percaya diri ketika menjalankan prosesi ritual. Para penabuh terbangan pun luluh dalam membawakan syair yang berisikan doa dengan fasih, secara sikologis agar anak tidak merasakan sakit pada saat disunat.

Fungsi musik di sini memiliki peranan yang sangat penting dalam suatu ritual, sebagaimana musik menjadi sarana. Syair lagu yang terkandung di dalam musik Oglor berperan sebagai penstabil konflik sosial dalam lingkup masyarakat beragama. 
Karena musik Oglor juga menghantarkan aturan-aturan religi dan syair lagu pun menetapkan hal-hal yang layak dan tidak layak dilakukan dalam masyarakat, seperti tentang apa yang harus dilakukan dan bagaimana melakukannya.

Musik memiliki fungsi dalam melambangkan suatu hal, seperti yang terdapat dalam musik Oglor di ritual sunatan. Pada saat prosesi anak dimandikan, Tujuan dimandikan yang dimaksud sebagai simbol sebagai anak harus menurut dengan orang tua sampai bisa menentukan jalan yang benar. Tujuan mandi sendiri dimaksudnya sebagai simbol anak yang sudah disunat dikemudian hari bisa menentukan jalan yang benar dan menjadi seseorang yang mandiri dan bisa membantu sesama (Wawancara dengan Senen, 12 November 2017). Tempo tabuhan pada bagia awal lambat, sebagai simbol anak harus nurut dengan orang tua sampai menemukan jalan yang benar. Tempo bagian kedua ganti dengan tempo cepat yaitu pada saat anak mandi sendiri, di bagian ini sebagai penggambaran ketikan sudah bisa menemukan jalan sendiri harus bisa menghadapi setiap rintangan yang ada dalam kehidupan.

Musik memiliki fungsi dalam pengintegrasian masyarakat, seperti musik Oglor dalam ritual sunatan yang dimainkan secara bersama-sama tanpa disadari musik tersebut menimbulkan rasa kebersamaan diantara pemain atau penonton. Musik Oglor di desa Wonokarto termasuk kesenian paling sering digunakan ketika ada upacara lain di masyarakat desa Wonokarto. Hanya dengan memainkan instrumen musiknya dan suara vokal ngelik yang khas, masyarakat desa Wonokarto pun datang untuk menonton dan membantu yang punya hajat. Pelaku musik Oglor sebagian besar adalah penduduk yang bermata pencaharian sebagai petani. Kegiatan masyarakat tersebut tercermin dari pemenuhan kebutuhan hidupnya yang dilakukan di sawah ataupun ladang setiap harinya. Hal itulah yang mendasari dalam proses silaturahmi antar anggota musik Oglor lebih terjaga, karena mereka hampir sebagian besar satu profesi. Dalam berkesenian, anggota musik Oglor dituntut untuk saling menerima saran serta masukan anggota musik Oglor lainnya. Hal ini terlihat ketika salah satu anggota musik Oglor salah dalam memainkan instrumennya, anggota lain akan memberikan masukan serta menyampaikan hal yang seharusnya dilakukan. 
Fungsi musik dalam hal ini, berisi tentang ajaran-ajaran untuk meneruskan sebuah system dalam kebudayaan terhadap generasi selanjutnya. Seperti yang terdapat pada musik Oglor, seni ini bernafaskan Islam yang memiliki aturan yang diselaraskan dengan norma-norma sosial pada masyarakat desa Wonokarto. Dengan kesinambungan ini sangat jelas musik Oglor sebagai stabilitas kebudayaan. Keberadaan musik Oglor merupakan warisan budaya yang diwariskan secara turuntemurun dan mampu dipertahankan serta masih terus dinikmati oleh masyarakat di desa Wonokarto. Hal ini terlihat bahwa masyarakat masih menjaga kesenian ini dikarenakan musik Oglor mempunyai keunikan dari kesenian ini, selain dari perpaduan dua budaya Islam dan Jawa, yaitu terletak pada suara vocal ngelik yang sangat tinggi.

Musik merupakan suara yang disusun sedemikian rupa sehingga mengandung irama, melodi, dan keharmonisan terutama suara yang dihasilkan dari alat-alat yang dapat menghasilkan bunyi-bunyian. Bunyi adalah benda yang bergetar dan dapat menghasilkan suara yang merambat melalui medium atau zat perantara hingga sampai ketelinga. Dengan memanfaatkan sifat bunyi yang merambat maka syair lagu dalam musik Oglor dapat difungsikan sebagai media atau sarana komunikasi masyarakat. Lagu Ngindama adalah lagu yang paling sering dimainkan dalam musik Oglor, sehingga lagu ini dapat digunakan sebagai media komunikasi untuk memberitahukan bahwa musik Oglor telah dimulai dengan harapan agar masyarakat dapat berkumpul untuk menyaksikan musik Oglor. Melodi yang terdapat dalam musik Oglor menggunakan pelarasan Pelog dan Slendro yang akrab di telinga masyarakat dengan begitu pengkomunikasian dengan masyarakat yang notabene suku Jawa akan lebih mudah sehingga pesan yang terdapat dalam syair lagu akan mudah tersampaikan, selain itu, nyanyian yang sudah terbaur antara bahasa Arab dan bahasa Jawa yang luluh menjadi satu kesatuan dengan demikian pengkomunikasian dengan masyarakat akan lebih mudah dan nilai-nilai Islam yang terkandung dalam musik Oglor akan mudah tersampaikan. 
Fungsi-fungsi yang ada pada musik Oglor diantaranya fungsi hiburan, biasanya ditujukan kepada orang-orang yang berpartisipasi dalam kegiatan tertentu ataupun mereka yang khusus menjadi penonton. Selain berfungsi sebagai sarana ritual, secara tidak langsung kesenian Oglor juga sebagai sarana hiburan bagi pemain dan keluarga yang hadir dalam upacara sunatan tersebut. Pertunjukan kesenian Oglor di masyarakat tidak bersifat komersil, sehingga masyarakat yang ingin menyaksikan tidak dipungut biaya untuk menyaksikan pertunjukan tersebut. Bagi pelaku seni kesenian Oglor mereka mendapatkan hiburan tersendiri dan mendapat kepuasan batin ketika pertunjukan mereka ditonton oleh banyak orang. Selain itu, kesenian Oglor juga berfungsi sebagai wadah untuk berinteraksi, bertukar pikiran dan pengalaman, meningkatkan kreatifitas, menambah eratnya tali persaudaraan baik sesama pelaku seni Oglor maupun dengan anggota kelompok kesenian lain.

\section{Kesimpulan}

Musik Oglor selalu digunakan sebagai media penghantar doa dihari besar agama dan terutama untuk upacara adat di desa Wonokarto. Seruan syair yang berisi doa dengan iringan instrumen kendang, sentik dan terbang menjadi satu kesatuan yang tak terpisahkan. Contohnya, musik Oglor sebagai pengiring jalannya prosesi sunatan di desa Wonokarto, yaitu sebelum prosesi pertama doa bersama untuk kelancaran jalannya upacara ritual, dilanjutkan prosesi pertama dengan mengarak anak dihantarkan ke lepen untuk membersihkan diri dari hal negatif. Prosesi kedua anak didoakan lagi sebelum disunat dan dilanjutkan malam harinya untuk acara slametan.

Dengan demikian dapat disimpulkan bahwa musik Oglor sebagai sarana upacara ritual sunatan di desa Wonokarto merupakan salah satu tradisi masyarakat desa Wonokarto, dimana pemilik hajat memilih menghadirkan musik Oglor pada setiap prosesi upacara ritual sunatan. Karena setiap syair lagu yang dilantunkan memiliki arti untuk kebaikan anak kedepannya dan dirayakan sebagai rasa syukur kepada Tuhan Yang Maha Esa. 
Musik Oglor merupakan kesenian yang dimana vokal lebih menonjol dibandingkan permainan instrumen musiknya. Instrumen yang digunakan dalam kesenian ini termasuk dalam kelompok instrumen membranophone, yang terdiri dari kendang, sentik, terbang. Di dalam seluruh serangkaian upacara ritual sunatan dari mulai awal prosesi, sampai selesai upacara ritual. Bentuk penyajian musik Oglor dalam upacara ritual sunatan membawakan lagu yang berisikan tentang nasehat kehidupan dan syair-syair Islam yang diambil dari kitab barzanji.

\section{Daftar Pustaka}

Amin, Darori. 2002. Islam \& Kebudayaan Jawa. Yogyakarta: Gama Media.

Poerwadarminta, WJS. 1984. Kamus Umum Bahasa Indonesia. Jakarta: PN Pustaka. Supanggah, Rahayu. 1995. Etnomusikologi. Yogyakarta: Yayasan Bentang Budaya. . 2009. Bothekan Karawitan II. Surakarta: Program Pascasarjana bekerjasama dengan ISI Press Surakarta.

\section{Narasumber}

Edi Suwito, 49, pelaku seni Oglor, Gareng Kidul, Ngadirojo, Pacitan.

Mbah Senen, 68, pelaku seni Oglor, petani, Wonokarto, Ngadirojo, Pacitan.

Tumian, 62, pelaku seni Oglor, petani, Wonokarto, Ngadirojo, Pacitan. Jaman, 72, pelaku seni Oglor, petani, Wonosobo, Ngadirojo, Pacitan. 